\title{
Imaging of cerebral blood flow in patients with severe traumatic brain injury in the neurointensive care
}

\author{
Elham Rostami ${ }^{1,2}{ }^{*}$, Henrik Engquist $^{3}$ and Per Enblad ${ }^{1}$ \\ 1 Section of Neurosurgery, Department of Neuroscience, Uppsala University, Uppsala, Sweden \\ 2 Department of Neuroscience, Karolinska Institutet, Stockholm, Sweden \\ ${ }^{3}$ Department of Surgical Sciences, Anaesthesiology and Intensive Care, Uppsala University, Uppsala, Sweden
}

Edited by:

Ibolja Cernak, University of Alberta,

Canada

\section{Reviewed by:}

Sonia Villapol, Georgetown University, USA

Bridgette D. Semple, University of California San Francisco, USA

\section{*Correspondence:}

Elham Rostami, Section of Neurosurgery, Department of Neuroscience, Uppsala University, Uppsala SE-751 85, Sweden

e-mail: elham.rostami@neuro.uu.se
Ischemia is a common and deleterious secondary injury following traumatic brain injury (TBI). A great challenge for the treatment of TBI patients in the neurointensive care unit (NICU) is to detect early signs of ischemia in order to prevent further advancement and deterioration of the brain tissue. Today, several imaging techniques are available to monitor cerebral blood flow (CBF) in the injured brain such as positron emission tomography (PET), single-photon emission computed tomography, xenon computed tomography (Xenon-CT), perfusion-weighted magnetic resonance imaging (MRI), and CT perfusion scan. An ideal imaging technique would enable continuous non-invasive measurement of blood flow and metabolism across the whole brain. Unfortunately, no current imaging method meets all these criteria. These techniques offer snapshots of the CBF. MRI may also provide some information about the metabolic state of the brain. PET provides images with high resolution and quantitative measurements of CBF and metabolism; however, it is a complex and costly method limited to few TBI centers. All of these methods except mobile Xenon-CT require transfer of TBI patients to the radiological department. Mobile Xenon-CT emerges as a feasible technique to monitor CBF in the NICU, with lower risk of adverse effects. Promising results have been demonstrated with Xenon-CT in predicting outcome in TBI patients. This review covers available imaging methods used to monitor CBF in patients with severe TBI.

Keywords: cerebral blood flow, brain injury, neurointensive care, Xenon-CT, imaging

\section{INTRODUCTION}

Traumatic brain injury (TBI) is one of the leading causes of death and disability in young adults. Acute TBI is characterized by a primary and a secondary injury. Primary brain injury is the direct injury to the brain parenchyma at the time of the initial impact, which can be both focal and diffuse depending on the biomechanics of the impact. The secondary brain injury is caused by a combination of neuronal and vascular damage, proteolytic pathways, excitotoxicity, oxygen-free radicals, apoptosis, inflammatory processes, and ischemia (1). Secondary brain injury may also be caused by secondary clinical events, e.g., increased intracranial pressure (ICP), hypotension, hypoxemia, seizures, and pyrexia (2).

Ischemia plays a major role in the pathology of TBI; signs of ischemic brain damage are found on autopsy in more than $90 \%$ of TBI patients $(3,4)$. Astrup et al. demonstrated that the critical ischemic cerebral blood flow (CBF) threshold for electri$\mathrm{cal} /$ functional disturbance was higher than the threshold for complete electrical failure/infarction, which was the foundation for the ischemic penumbra concept $(5,6)$. Jones et al. showed that the risk of infarction was dependent both of the CBF level and duration of time with decreased CBF (7). Furthermore, the degree and duration of decreased CBF was shown to be decisive of the outcome (8) and correlated with injury severity following TBI $(9,10)$.

Another important observation was the "luxury perfusion syndrome" originally described by Lassen (11). This syndrome was described as cerebral hyperemia or "over-abundant CBF relative to the metabolic needs of the brain tissue." Cerebral hyperemia following brain injury has been demonstrated in several studies using intravenous Xenon-133 $(12,13)$. Normal and high CBF with narrow arteriojugular venous difference of oxygen $\left(\mathrm{AVDO}_{2}\right)$ indicating "luxury perfusion" has been shown in comatose TBI patients (14).

Areas surrounding the focal regions of reduced CBF display milder reductions in flow following TBI $(15,16)$. It has been suggested that this area is at risk for secondary insults but most importantly, due to its viability, it is sensitive to therapeutic interventions (17).

The brain has almost no capacity to survive without oxygen. Its reserved oxygen capacity will only last for a few seconds. The brain adenosine triphosphate (ATP), the fuel crucial for neuronal functioning, will only last for $40 \mathrm{~s}$ during complete ischemia (18). Furthermore, the level of ATP in brain tissue following TBI has been shown to correlate to the severity of the brain injury (19).

Mean arterial pressure (MAP), ICP, $\mathrm{PaCO}_{2}$, and $\mathrm{PaO}_{2}$ are the physiologic variables that would influence CBF. The most important relationship, however, is the principle of flow-metabolism coupling whereby cerebral metabolic rate of oxygen $\left(\mathrm{CMRO}_{2}\right)$ is directly related to $\mathrm{CBF}$ and $\mathrm{AVDO}_{2}$ (20).

Changes in CBF following TBI in patients have been described as a triphasic pattern. During the first and acute phase, there is a 
$50 \%$ decrease in CBF $(21,22)$. During the following initial $12 \mathrm{~h}$ post-injury, the second phase begins, marked by a rise in CBF that approaches or exceeds normal values in some patients and typically persists for the next $4-5$ days (23). This phase is followed in turn by a third period of low CBF that lasts for up to 2 weeks postinjury. However, there is a strong heterogeneity of $\mathrm{CBF}$ among TBI patients. In some patients, the CBF may persist low while in others normal CBF values can be seen that remains for days to weeks. The assessment of CBF following TBI is important to detect episodes of ischemia. Ischemia in TBI patients regardless of when detected has shown to be correlated with poor outcome $(21,23,24)$. It is important to relate CBF changes to the metabolic demand where both metabolic depression and transient hyperglycolysis following TBI have been observed (25-27). The episodes of high CBF paralleled the episodes of hyperglycolysis and the question was raised whether low CBF in patients following TBI always means an inadequate supply for metabolic demand. Combining CBF imaging with microdialysis could show that high lactate/pyruvate ratio, usually interpreted as ischemia, occurred despite that the CBF was not low (28). This suggested that the metabolic crises can be caused by mitochondrial dysfunction rather than inadequate $\mathrm{CBF}$.

A great challenge for the treatment of TBI patients in the neurointensive care unit (NICU) is to detect early signs of secondary brain injury in order to prevent further advancement and deterioration of the brain tissue. Multimodality monitoring using focal and global methods provides valuable information but has its limitations. Imaging of the brain may add important information. An ideal imaging technique would enable continuous non-invasive measurement of regional blood flow and metabolism across the whole brain. Currently, there are several methods that offer snapshots of the CBF, and some also provides information about the metabolic state of the injured brain. The aim of this article is to give a short review of currently available brain imaging methods used in patients with severe TBI. Relevant references are summarized in Table 1.

\section{POSITRON EMISSION TOMOGRAPHY}

Positron emission tomography (PET) is an imaging technique that provides quantitative measurement of cerebral perfusion and metabolism $(78,79)$. Positron emitting radionuclides are used either after incorporation into chemical compounds (e.g., $\mathrm{C}^{15} \mathrm{O}$, $\mathrm{C}^{15} \mathrm{O}_{2}$, and $\mathrm{H}_{2}{ }^{15} 0$ ) or as molecular tracers (e.g., ${ }^{15} \mathrm{O}_{2}$ ). After intravenous administration or inhalation, the isotopic tracer is distributed in the tissues according to the physiological properties, and the radioactive tracer concentration is measured regionally. The radioisotopes, which are produced by a cyclotron, have short half-life and must be used without delay. The detected regional tracer concentrations allows for mathematical quantification of $\mathrm{CBF}$, cerebral blood volume (CBV), the oxygen extraction fraction (OEF), and $\mathrm{CMRO}_{2}$ (80-82).

$\mathrm{O}^{15}$-radioisotope has been used to measure $\mathrm{CBF}$ and $\mathrm{OEF}$, while $\mathrm{F}^{19}$ deoxyglucose (FDG) assesses regional brain glucose metabolism. FDG is analogous to glucose in the body. It rapidly crosses the blood-brain barrier and is taken up into brain cells. Since FDG is not further metabolized, it can be imaged to produce metabolic maps for PET imaging. The images obtained are then generally co-registered with $\mathrm{CT}$ or magnetic resonance imaging (MRI) to obtain anatomic relationships $(78,79,83)$.

Several studies have used PET in assessment of TBI $(27,28,59$, 60, 62-64, 84-86).

Regional brain ischemia was detected in TBI patients, who underwent PET within $24 \mathrm{~h}$ following injury according to $\mathrm{CBF}$, $\mathrm{OEF}$, and $\mathrm{CMRO}_{2}$ measurements, and an increase of the ischemic volume was correlated with poor outcome (61).

By using PET, both hypo- and hyperglycolysis have been demonstrated in TBI patients. In a study performed by Bergsneider et al., it was shown that both global and regional hyperglycolysis occur following severe TBI. Within 1 week following injury, 56\% of the patients showed evidence of hyperglycolysis using FDGPET (27). In a follow-up study, PET was performed within 4 days following TBI, and a depressed cerebral metabolic rate of glucose was observed (63).

Combining PET with microdialysis in TBI patients, Vespa et al. demonstrated high lactate/pyruvate ratio that indicates metabolic crises without presence of ischemia according to PET (28). It was suggested that high lactate/pyruvate ratio under those circumstances indicated mitochondrial dysfunction rather than ischemia $(28,87,88)$.

One of the advantages of PET is that it can generate images of greater resolution. The main advantage is that PET provides the possibility to obtain quantitative regional measurements of both CBF and metabolism. The drawbacks are that the generation of isotopes requires a costly cyclotron and is labor intensive. In addition, the isotopes that are used have a shorter half-life thereby requiring that the radiopharmaceuticals must be readily available. Furthermore, PET provides a non-continuous measurement and the need for transfer of the patient to a radiology unit $(61,89)$.

\section{SINGLE-PHOTON EMISSION COMPUTED TOMOGRAPHY}

The principal of single-photon emission computed tomography (SPECT) is similar to PET in using radioactive material to detect gamma rays. The tracer usually used is the radioisotope ${ }^{99 \mathrm{~m}} \mathrm{Tc}$ that crosses the blood-brain barrier and localize in the brain tissue in proportion to blood flow. SPECT is a semi-quantitative $\mathrm{CBF}$ measurement technique that is based on the calculation of tracer uptake ratios and an estimation of the relative regional CBF (rCBF) distribution within the brain (90).

An initial study lesions detected by SPECT in TBI patients during the first $72 \mathrm{~h}$ was compared to CT findings. It was shown that SPECT detected $40 \%$ more lesions than shown by CT scans (65). Similar results have been reported by Roper et al. (66). In a study of eight patients with severe diffuse TBI, SPECT revealed several lesions in all patients, even in non-depicted regions on MRI (67). Abnormalities in cerebral perfusion were also observed 1-6 months following injury.

There are numerous publications proving SPECT functional brain imaging as a powerful research tool, especially in the fields of cerebrovascular disease and cognitive disorders, and there is extensive development in receptor and molecular imaging (91). In a recent systematic review, Raji et al. concluded that SPECT imaging could be useful in evaluating patients with neurological and psychiatrically sequela after TBI (92). 
Table 1 | Presents a summary of publications using Xenon-CT, PET, perfusion CT, perfusion-MRI, and comparative studies using different imaging modalities.

\begin{tabular}{|c|c|c|c|c|c|}
\hline Reference & Subject & Additional monitoring & Time post-injury & $n$ & GCS \\
\hline \multicolumn{6}{|l|}{ XENON-CT } \\
\hline Langfitt et al. (31) & $\begin{array}{l}\text { Imaging pathology and } \\
\text { neuropsychological tests (133Xe) }\end{array}$ & $\begin{array}{l}\text { MRI, PET, CT, } \\
\text { Xenon-133 }\end{array}$ & Acute and 6 months & 3 & $\mathrm{GCS} \leq 13$ \\
\hline Marion et al. (21) & Xenon-CT and ICP & & Within 7 days & 23 & $\mathrm{GCS} \leq 8$ \\
\hline Schalen et al. (33) & $\begin{array}{l}\text { CBF and hyperventilation response } \\
(133 \mathrm{Xe})\end{array}$ & Jugbulb & During NIC stay & 38 & $\mathrm{GCS} \leq 8$ \\
\hline Marion et al. (21) & CBF following TBI & & $1 \mathrm{~h}-7$ days & 32 & $\mathrm{GCS} \leq 7$ \\
\hline Bouma et al. (23) & Early measurement of CBF in TBI & Jugbulb & First $24 \mathrm{~h}$ & 186 & $\mathrm{GCS} \leq 8$ \\
\hline Stringer et al. (34) & CBF and hyperventilation & & During NIC stay & 12 & \\
\hline Bouma and Muizelaar (35) & Xenon-CT evaluation in TBI & & & & \\
\hline McLaughlin and Marion (36) & $\mathrm{CBF}$ and vasoresponsivity in contusions & & $24-48 h$ & 10 & $\mathrm{GCS} \leq 8$ \\
\hline Kelly et al. (37) & CBF and outcome (133Xe) & & $1-5$ days & 54 & $\mathrm{GCS} \leq 12$ \\
\hline Schroder et al. (38) & $\begin{array}{l}\text { Relation of CBV and CBF to explain } \\
\text { cause of ischemia }\end{array}$ & $\begin{array}{l}\text { Dynamic CT imaging } \\
\text { (CBV) }\end{array}$ & $24 \mathrm{~h}$ & 51 & $\mathrm{GCS} \leq 8$ \\
\hline Bouma et al. (39) & Underlying cause of cerebral swelling & $\begin{array}{l}\text { Dynamic CT imaging } \\
\text { (CBV) }\end{array}$ & Early posttrauma & 37 & \\
\hline Schutt et al. (44) & Thermo-dye-dilution and Xenon-CT & Thermo-dye-dilution & $1-5$ days & 16 & $\mathrm{GCS} \leq 8$ \\
\hline Valadka et al. (45) & $\mathrm{CBF}$ and pbr02 & pbr02 & & 18 & $\mathrm{GCS} \leq 6$ \\
\hline Furuya et al. (46) & CBF and hypodense area & & & 50 & $\mathrm{GCS} \leq 8$ \\
\hline Chieregato et al. (47) & $\begin{array}{l}\mathrm{rCBF} \text { in traumatic hemorrhagic } \\
\text { contusions }\end{array}$ & & & 14 & $\mathrm{GCS} \leq 9$ \\
\hline Chieregato et al. (48) & CBF and hypertension & & & 7 & $\mathrm{GCS} \leq 8$ \\
\hline Chieregato et al. (49) & Recovery of $\mathrm{CBF}$ in $\mathrm{tICH}$ & & First 20 day & 22 & $\mathrm{GCS} \leq 8$ \\
\hline Inoue et al. (50) & $\mathrm{CBF}$ and 6 months outcome & & $1,2,3,4,6$ weeks & 20 & $\mathrm{GCS} \leq 8$ \\
\hline Chieregato et al. (51) & $\begin{array}{l}\text { CBF in hematomas and traumatic } \\
\text { contusions }\end{array}$ & & & 43 & $\mathrm{GCS} \leq 8$ \\
\hline Poon et al. (52) & $\begin{array}{l}\text { C02 reactivity and cerebral } \\
\text { hemodynamics }\end{array}$ & TCD, ICP, Microdialysis & & 35 & $\mathrm{GCS} \leq 12$ \\
\hline Marmarou et al. (53) & Type of edema in diffuse and focal TBI & DWI, MR & & 45 & $\mathrm{GCS} \leq 8$ \\
\hline
\end{tabular}




\section{Table 1 | Continued}

\begin{tabular}{|c|c|c|c|c|c|}
\hline Reference & Subject & Additional monitoring & Time post-injury & $n$ & GCS \\
\hline Masaoka (55) & CBF during hypothermia & Jugbulb & $1-4$ days & 30 & $\mathrm{GCS} \leq 8$ \\
\hline Robertson et al. (56) & Genetic polymorphism of N03 and CBF & & 12 and $48 h$ & 51 & $\mathrm{GCS} \leq 8$ \\
\hline Kaloostian et al. (57) & $\begin{array}{l}\text { Outcome prediction within } 12 \mathrm{~h} \\
\text { following } \mathrm{TBI}\end{array}$ & & $12 \mathrm{~h}$ & 120 & $\mathrm{GCS} \leq 8$ \\
\hline \multicolumn{6}{|l|}{ PET } \\
\hline Bergsneider et al. (27) & Cerebral hyperglycolysis in TBI patients & & $1-24 \mathrm{~h}$ & 28 & $\mathrm{GCS} \leq 8$ \\
\hline Hattori et al. (59) & $\begin{array}{l}\text { Metabolic rate of glucose and level of } \\
\text { consciousness }\end{array}$ & & $1-5$ days & 23 & $\mathrm{GCS} \leq 15$ \\
\hline Hattori et al. (62) & $\begin{array}{l}\text { characterize contusional, } \\
\text { pericontusional, and remote regions in } \\
\text { TBI }\end{array}$ & & $1-5$ days & 21 & GCS 3-15 \\
\hline Wu et al. (63) & Metabolic rate of glucose in gray matter & & 1-4 days & 14 & $\mathrm{GCS} \leq 14$ \\
\hline Cunningham et al. (64) & Threshold for irreversible tissue damage & & $1-5$ days & 14 & $\mathrm{GCS} \leq 8$ \\
\hline Vespa et al. (28) & Microdialysis and PET & & Mean $36 \mathrm{~h}$ & 19 & $\mathrm{GCS} \leq 14$ \\
\hline \multicolumn{6}{|l|}{ SPECT } \\
\hline Abdel-Dayem et al. (65) & SPECT correlated to CT & & $24 \mathrm{~h}$ & 14 & $\mathrm{GCS} \leq 8$ \\
\hline Soustiel et al. (70) & Prognostic value of admission CBF & & At admission and I week & 30 & $\mathrm{GCS} \leq 9$ \\
\hline Huang et al. (71) & Progression of cerebral contusions & & $1-6 h$ & 22 & $\mathrm{GCS} \leq 8$ \\
\hline Bendinelli et al. (72) & $\mathrm{CBF}$ within the first $48 \mathrm{~h}$ following TBI & & $1-48 \mathrm{~h}$ & 30 & $\mathrm{GCS} \leq 8$ \\
\hline \multicolumn{6}{|l|}{ PERFUSION-MRI } \\
\hline Garnett et al. (73) & rCVB in contusion & & 2-19 days & 18 & $\mathrm{GCS} \leq 8 \mathrm{vs} . \geq 9$ \\
\hline \multicolumn{6}{|l|}{ COMPARATIV STUDIES } \\
\hline Hagen et al. (74) & Comparison PW-MRI and Xenon-CT & & $1-24 \mathrm{~h}$ & 10 & Stenosis, HCF, atrophy \\
\hline Rempp et al. (75) & PW-MRI and PET in healthy subjects & & & 12 & NC \\
\hline Gillard et al. (76) & $\begin{array}{l}\text { Comparison CTP and PET in AVM and } \\
\text { gliomas }\end{array}$ & & & 8 & 8 AVM, 2 glioma \\
\hline Campbell et al. (77) & $\begin{array}{l}\text { Comparison PW-MRI and perfusion CT } \\
\text { in ischemic stroke }\end{array}$ & & $3-6 h$ & 49 & Acute stroke \\
\hline
\end{tabular}

CBF, cerebral blood flow; ICP, intracranial pressure; CPP, cerebral perfusion pressure; CT, computer tomography; rCBV, regional cerebral blood flow; $t / C H$, traumatic intracranial hematoma; pbrO2, partial brain oxygen tension; Jugbulb, jugular bulb; INVOS, brain tissue oxygen saturation. 
Although SPECT provide images with lower resolution than PET, the radioisotope is significantly less expensive and longer lasting with no need of cyclotrons. Implementation of SPECT into clinical routine for estimation of $\mathrm{rCBF}$ in the acute phase of TBI is however lacking.

\section{STABLE XENON COMPUTED TOMOGRAPHY}

Xenon computed tomography (Xenon-CT) utilizes inhalation of a gas mixture containing 28\% (30-35\% in older studies) nonradioactive xenon $\left({ }^{131} \mathrm{Xe}\right)$ and oxygen. The Xenon gas is a radio opaque, highly lipid soluble and capable of crossing the BBB. The Kety-Schmidt equation is applied to measure regional and global CBF. It provides primarily measurements of rCBF in the cortex and has been used under a variety of clinical conditions to study the pathophysiology and guide therapy regarding blood pressure and ventilation management (29). The first report of Xenon-CT in a TBI patient demonstrated that this technique could be used to detect regions with loss of autoregulation and $\mathrm{CO}_{2}$ reactivity (30). In a following Xenon-CT study including 35 TBI patients, the feasibility of using Xenon-CT for detecting changes in CBF, for guidance of the degree of hyperventilation, and for the identification of brain death was evaluated (32). Higher incidence of ischemia (very low CBF) than previously assumed following TBI could be demonstrated by Xenon-CT (35), which also was shown to be associated to high early mortality (22). Studies on contusions following TBI have shown that the CBF is concentrically distributed, improving from the core to the periphery (47). In traumatic hematomas, it was shown that low rCBF levels seen in the perihematoma low-density area CBF recovered from day 2 and forward and persistence ischemia was only seen in the core (49). It appears that type of contusion is also determinant of $\mathrm{rCBF}$, with lower values in mixed contusions compared to hamorrhagic and non-hamorrhagic contusions (42).

The Xenon-CT has also been used to evaluate the effect of different interventions performed in the NICU on CBF following TBI. Chieregato et al. observed that rCBF in the intracontusional low-density area having critically reduced initial values was marginally affected by norepinephrine induced increase in cerebral perfusion pressure (CPP). However, in subjects starting from non-critical baseline values, $\mathrm{rCBF}$ was significantly reduced (48). Stringer et al. reported that hyperventilation in patients with acute brain lesion reduced CBF substantially both within the lesion and in apparently normal brain regions (34). Furthermore, the CBF in contusions has been shown to be reduced but with preserved $\mathrm{CO}_{2}$ reactivity. It was suggested that this area and the surrounding parenchyma are hypersensitive to hyperventilation and hypotension and thus vulnerable to secondary injury (36). The $\mathrm{CO}_{2}$ reactivity has been suggested as a good early prognostic indicator (41). In the study by Kushi et al., jugular bulb catheters were used in combination with Xenon-CT. Xenon-CT with simultaneous multimodality monitoring have generated interesting results regarding $\mathrm{CBF}$ and metabolism following TBI. Combining Xenon$\mathrm{CT}$ with cerebral microdialysis showed that loss of $\mathrm{CO}_{2}$ reactivity was associated with increased ICP and increased lactate, glutamate and glycerol dialyzate levels, and consistently a fatal outcome (52). In another study, areas with low CBF showed increased levels of glutamate (40).
Xenon computed tomography has also been combined with tissue oxygen tension monitoring in TBI, and it showed a linear relationship between $\mathrm{pbrO}_{2}$ and $\mathrm{CBF}$ (45).

Promising results have been demonstrated with Xenon-CT in predicting outcome in TBI patients. Patients with low CBF that returns to normal 2-3 weeks following severe TBI show better neurological outcome that the group who had sustained low CBF (50).

In a recent study, Xenon-CT was used to monitor CBF in the first $12 \mathrm{~h}$ following injury in $120 \mathrm{TBI}$ patients. It was shown that measurement of CBF within the first $12 \mathrm{~h}$ predicts 6 months outcome, and the best outcome prediction was obtained if Xenon-CT was measured within $6 \mathrm{~h}$ following TBI (57). In TBI, patient with pulmonary injury care should be taken in CBF analyses since endtidal and arterial xenon concentration curves can be a source of error (43).

Previous studies indicate that endothelial nitric oxide synthase $\left(\mathrm{NO}_{3}\right)$ activity is important in maintaining CBF after TBI. Using Xenon-CT, Robertson et al. studies the association of genetic polymorphism of $\mathrm{NO}_{3}$ and $\mathrm{CBF}$ following TBI. They showed that patients with the $\mathrm{C} / \mathrm{C}$ genotype had lowest $\mathrm{CBF}$ values and worse outcome (56).

Xenon computed tomography is fast and provides quantitative measurements of CBF. The big advantage is that by using a mobile CT scanner there are no need to transport the patient to a different setting, which is always associated with increase risk of adverse events $(93,94)$. Other advantages are the short half-life and very low risk of side effects of inhaled Xenon, which makes repeated examinations more feasible. The very low risk of side effects was demonstrated in a recent multicentre evaluation study concluding that CBF measurements by Xenon-CT can be performed safely, with a very low risk of adverse events, and no risk of permanent morbidity or sequela could be detected (95). However, the brain is exposed to a small dose of radiation.

Wintermark et al. reported a radiation dose of 3.5-10 $\mathrm{mSv}$ for the whole xenon study (96). While Seifert et al. report that in the case of brain partially located in the region of primary radiation, a mean organ dose of $39 \mathrm{mSv}$ was calculated, corresponding to an effective does of $1.6 \mathrm{mSv}$ (97).

In our hands, the effective dose for a complete Xenon-CT examination is $2.7 \mathrm{mSv}$ (in-house investigation, data not published). This dose can be compared to an annual mean background dose in Sweden of $3 \mathrm{mSv}$.

\section{BRAIN PERFUSION IMAGING}

Cerebral perfusion is defined as the steady-state delivery of blood to brain tissue per unit volume, measured in milliliters per $100 \mathrm{~g}$ of tissue per minute. Perfusion imaging uses intravascular tracers most commonly iodine or gadolinium contrasts depending on imaging method. These methods take advantage of signal changes that accompany the passage of tracer through the cerebrovascular system. Contrasts used in MRI, such as gadolinium, are compounds that work by altering the magnetic properties of nearby hydrogen nuclei, while CT perfusion uses iodine contrast agents, which are radiopaque (such as iohexol) $(98,99)$.

The data acquired can be used to generate color-coded maps and quantification of various perfusion parameters, including 
CBF, CBV, mean transit time (MTT), and time to peak (TTP; the time from the start of contrast agent injection to the time of maximum enhancement). The two commonly used methods are perfusion-MRI and CT perfusion and will be discussed below.

\section{PERFUSION-WEIGHTED MRI}

The most common technique for measuring perfusion parameters with MRI is dynamic susceptibility contrast (DSC). DSC-MRI perfusion is also known as bolus-tracking MRI or perfusion-weighted MRI (PW-MRI). We chose PW-MRI throughout this review. In PW-MRI, a time series of fast T2-weighted images are acquired when gadolinium contrast agent is injected. As gadolinium passes through the tissues, it produces a reduction of $\mathrm{T} 2$ intensity depending on the local concentration. Curves showing intensity changes based on the concentration of gadolinium over time can be generated. This time-to-signal intensity alteration can be processed to extract parameters that reflect either CBF, CBV, or MTT. These are linked by the equation $\mathrm{CBF}=\mathrm{CBV} / \mathrm{MTT}$, also known as the "central volume principle" $(100,101)$.

Studies on TBI using PW-MRI are limited. Garnett et al. used PWI during the subacute phase of TBI in a small group of patients and reported that regions of both normal-appearing and contused brain may have an abnormal regional CBV and had worse outcome (73). In a study including 10 patients with neurological illness, PW-MRI was compared with Xenon-CT and showed a good correlation of rCBF between these methods (74).

Perfusion-weighted MRI can be used together with diffusionweighted MRI (DWI), then the ischemic penumbra can be identified $(102,103)$. It can assess vascular patency if magnetic resonance angiography (MRA) is added (104). PW-MRI was used in healthy subjects to measure absolute values of $\mathrm{rCBF}$ and $\mathrm{rCBV}$ and compares these to values obtained by PET. The values were in agreement with previous findings using PET both in white and gray matter (75). In a recent study, PW-MRI was compared with CT perfusion, and it was found that PW-MRI is superior in precision and accuracy in identifying ischemic core and salvageable tissue (77).

One of the advantages of PW-MRI is that the contrast agent used is gadolinium that has fewer contraindications than iodinated contrasts.

However, compared to CT scan the PW-MRI is relatively timeconsuming and more expensive. MRI scans are also less available and more difficult to monitor patients in.

\section{COMPUTED TOMOGRAPHY PERFUSION SCAN}

In computed tomography perfusion (CTP), a native (unenhanced) $\mathrm{CT}$ is obtained followed by infusion of iodinated contrast. The concurrent acquisition of images after contrast injection allow for the measurement of changes in tissue attenuation that occur in the brain with time. Post processing of the data allows the generation of color-coded maps and quantification of various perfusion parameters, including CBF, CBV, MTT, and TTP. CTP has been mainly used in the management of patients with acute stroke and other cerebrovascular disorders since it provides an easy and practical way of obtaining both structural and CBF pictures. The first study performed with CTP in severe TBI included 130 patients and suggested that the number of arterial territories with low rCBV values was an independent prognostic factor regarding functional outcome (69). Same group examined the correlation of CPP and CTP findings. They could discriminate between two groups of patients; one without relationship between $\mathrm{CBF}$ and corresponding CPP values, considered as preserved autoregulation and the other group with strong correlation between $\mathrm{CBF}$ and CPP, interpreted as impaired autoregulation. Interestingly, the group with impaired autoregulation showed better clinical outcome (68).

Two studies have examined cerebral contusions using CTP in patients with TBI. In the first study, both contusional core and the surrounding brain tissue were examined. It was shown that early CBV and CBF maps corresponds better than an early native CT scan with the findings of non-contrast CT scans after 1 week, and therefore, CTP provides better early evaluation of tissue viability (70). In the second study, CTP was performed within $6 \mathrm{~h}$ of arrival, and contrast extravasation was predictive of hemorrhage progression (71). A recent study performed CTP during the first $48 \mathrm{~h}$ following severe TBI and confirmed abnormal perfusion following TBI and detected areas of hypoperfusion in $60 \%$ of patients that were not seen in conventional CT (72).

Measurement of CBF using CTP was compared with PET in patients with arteriovenous malformations and gliomas. Good correlation was found, although CTP had a tendency to overestimate CBF (76).

The advantages of CTP are that all units equipped with a CT scanner can obtain perfusion images and it is fast. Disadvantages include the exposure to radiation, potential for an allergic reaction to the iodine contrast, contraindication to use iodine contrast in case of renal insufficiency and the risk of inducing renal failure with repeated examinations, and the need to predetermine the regions of interest before the scan. Furthermore, although quantitative values can be acquired with perfusion CT, the accuracy of the flow values obtained has not been fully validated. It has not been determined if the references for normal CBF and critical CBF thresholds as measured with PET or Xenon-CT can be applied in perfusion CT. Perfusion CT uses an intravascular tracer to measure intravascular CBF, which likely reflects a different physiologic mechanism than that of PET and Xenon-CT, which employ a diffusible trace.

\section{CONCLUSION}

Cerebral hypoperfusion and other CBF disturbances are common after TBI and play an important role in the development of secondary brain injury. It has been difficult to integrate methods for quantitative rCBF measurements in neurointensive care, which relies mainly on uni-focal or global monitoring methods to detect cerebral ischemia or to evaluate different treatments aimed at increasing CBF. There is a need of a rapid assessment of $\mathrm{CBF}$ in the NIC unit without transportation of the patient. Currently, bedside Xenon-CT is the only method fulfilling these criteria. All other methods discussed above require transfer of TBI patients to the radiological department. However, Xenon-CT can only provide quantitative measurements of CBF. In order to assess parameters such as CBV, $\mathrm{CMR}_{\text {glu }}$, and $\mathrm{CMRO}_{2}$, it is necessary to use perfusion imaging and PET. PET is a complex and costly procedure with a need of cyclotron, 
which has limited its use to few TBI centers. None of the current available methods provide continuous measurements of $\mathrm{CBF}$.

Bedside Xenon-CT emerges as an economical and more accessible imaging technique with few adverse effects that can be used in the routine NIC to measure CBF following TBI.

\section{REFERENCES}

1. Werner C, Engelhard K. Pathophysiology of traumatic brain injury. Br J Anaesth (2007) 99:4-9. doi:10.1093/bja/aem131

2. Rose J, Valtonen S, Jennett B. Avoidable factors contributing to death after head injury. Br Med J (1977) 2:615-8. doi:10.1136/bmj.2.6087.615

3. Graham DI, Adams JH, Doyle D. Ischaemic brain damage in fatal non-missile head injuries. J Neurol Sci (1978) 39:213-34. doi:10.1016/0022-510X(78) 90124-7

4. Graham DI, Ford I, Adams JH, Doyle D, Teasdale GM, Lawrence AE, et al. Ischaemic brain damage is still common in fatal non-missile head injury. $J$ Neurol Neurosurg Psychiatry (1989) 52:346-50. doi:10.1136/jnnp.52.3.346

5. Astrup J, Symon L, Branston NM, Lassen NA. Cortical evoked potential and extracellular $\mathrm{K}+$ and $\mathrm{H}+$ at critical levels of brain ischemia. Stroke (1977) 8:51-7.

6. Astrup J, Siesjo BK, Symon L. Thresholds in cerebral ischemia - the ischemic penumbra. Stroke (1981) 12:723-5.

7. Jones TH, Morawetz RB, Crowell RM, Marcoux FW, Fitzgibbon SJ, Degirolami $\mathrm{U}$, et al. Thresholds of focal cerebral ischemia in awake monkeys. J Neurosurg (1981) 54:773-82. doi:10.3171/jns.1981.54.6.0773

8. Heiss WD, Rosner G. Functional recovery of cortical neurons as related to degree and duration of ischemia. Ann Neurol (1983) 14:294-301. doi:10.1002/ ana.410140307

9. Graham DI, Adams JH. Ischaemic brain damage in fatal head injuries. Lancet (1971) 1:265-6. doi:10.1016/S0140-6736(71)91003-8

10. Dietrich WD, Alonso O, Busto R, Prado R, Zhao W, Dewanjee MK, et al. Posttraumatic cerebral ischemia after fluid percussion brain injury: an autoradiographic and histopathological study in rats. Neurosurgery (1998) 43:585-93; discussion 593-84. doi:10.1097/00006123-199809000-00105

11. Lassen NA. The luxury-perfusion syndrome and its possible relation to acute metabolic acidosis localised within the brain. Lancet (1966) 2:1113-5. doi:10.1016/S0140-6736(66)92199-4

12. Bruce DA, Langfitt TW, Miller JD, Schutz H, Vapalahti MP, Stanek A, et al. Regional cerebral blood flow, intracranial pressure, and brain metabolism in comatose patients. J Neurosurg (1973) 38:131-44. doi:10.3171/jns.1973.38.2. 0131

13. Enevoldsen EM, Cold G, Jensen FT, Malmros R. Dynamic changes in regional $\mathrm{CBF}$, intraventricular pressure, $\mathrm{CSF} \mathrm{pH}$ and lactate levels during the acute phase of head injury. J Neurosurg (1976) 44:191-214. doi:10.3171/jns.1976.44.2.0191

14. Obrist WD, Langfitt TW, Jaggi JL, Cruz J, Gennarelli TA. Cerebral blood flow and metabolism in comatose patients with acute head injury. Relationship to intracranial hypertension. J Neurosurg (1984) 61:241-53. doi:10.3171/jns. 1984.61.2.0241

15. DeWitt DS, Jenkins LW, Wei EP, Lutz H, Becker DP, Kontos HA. Effects of fluid-percussion brain injury on regional cerebral blood flow and pial arteriolar diameter. J Neurosurg (1986) 64:787-94. doi:10.3171/jns.1986.64.5.0787

16. Dietrich WD, Alonso O, Busto R, Prado R, Dewanjee S, Dewanjee MK, et al. Widespread hemodynamic depression and focal platelet accumulation after fluid percussion brain injury: a double-label autoradiographic study in rats. $J$ Cereb Blood Flow Metab (1996) 16:481-9. doi:10.1097/00004647-19960500000015

17. Bramlett HM, Green EJ, Dietrich WD. Exacerbation of cortical and hippocampal CA1 damage due to posttraumatic hypoxia following moderate fluidpercussion brain injury in rats. J Neurosurg (1999) 91:653-9. doi:10.3171/jns. 1999.91.4.0653

18. Siesjo BK. Brain Energy Metabolism. New York, NY: John \& Wiley (1978).

19. Marklund N, Salci K, Ronquist G, Hillered L. Energy metabolic changes in the early post-injury period following traumatic brain injury in rats. Neurochem Res (2006) 31:1085-93. doi:10.1007/s11064-006-9120-0

20. Reilly PL, Bullock R. Head Injury, Pathophysiology and Management. London: Hodder Education (2005)
21. Marion DW, Darby J, Yonas H. Acute regional cerebral blood flow changes caused by severe head injuries. J Neurosurg (1991) 74:407-14. doi:10.3171/jns. 1991.74.3.0407

22. Bouma GJ, Muizelaar JP, Stringer WA, Choi SC, Fatouros P, Young HF. Ultraearly evaluation of regional cerebral blood flow in severely head-injured patients using xenon-enhanced computerized tomography. J Neurosurg (1992) 77:360-8. doi:10.3171/jns.1992.77.3.0360

23. Bouma GJ, Muizelaar JP, Choi SC, Newlon PG, Young HF. Cerebral circulation and metabolism after severe traumatic brain injury: the elusive role of ischemia. J Neurosurg (1991) 75:685-93. doi:10.3171/jns.1991.75.5.0685

24. Overgaard J, Mosdal C, Tweed WA. Cerebral circulation after head injury. Part 3: does reduced regional cerebral blood flow determine recovery of brain function after blunt head injury? J Neurosurg (1981) 55:63-74. doi:10.3171/jns. 1981.55.1.0063

25. Jaggi JL, Obrist WD, Gennarelli TA, Langfitt TW. Relationship of early cerebral blood flow and metabolism to outcome in acute head injury. J Neurosurg (1990) 72:176-82. doi:10.3171/jns.1990.72.2.0176

26. Hovda DA, Lee SM, Smith ML, Von Stuck S, Bergsneider M, Kelly D, et al. The neurochemical and metabolic cascade following brain injury: moving from animal models to man. J Neurotrauma (1995) 12:903-6. doi:10.1089/neu.1995. 12.903

27. Bergsneider M, Hovda DA, Shalmon E, Kelly DF, Vespa PM, Martin NA, et al. Cerebral hyperglycolysis following severe traumatic brain injury in humans: a positron emission tomography study. JNeurosurg (1997) 86:241-51. doi:10.3171/jns.1997.86.2.0241

28. Vespa P, Bergsneider M, Hattori N, Wu HM, Huang SC, Martin NA, et al. Metabolic crisis without brain ischemia is common after traumatic brain injury: a combined microdialysis and positron emission tomography study. J Cereb Blood Flow Metab (2005) 25:763-74. doi:10.1038/sj.jcbfm.9600073

29. Yonas H, Gur D, Wolfson SK Jr, Good WF, Good BC, Latchaw RE. Xenonenhanced computerised tomographic cerebral blood flow mapping. Lancet (1984) 1:1357. doi:10.1016/S0140-6736(84)91856-7

30. Yonas H, Snyder JV, Gur D, Good WF, Latchaw RE, Wolfson SK Jr, et al. Local cerebral blood flow alterations (Xe-CT method) in an accident victim. J Comput Assist Tomogr (1984) 8:990-1. doi:10.1097/00004728-198410000-00038

31. Langfitt TW, Obrist WD, Alavi A, Grossman RI, Zimmerman R, Jaggi J, et al. Computerized tomography, magnetic resonance imaging, and positron emission tomography in the study of brain trauma. Preliminary observations. $J$ Neurosurg (1986) 64:760-7. doi:10.3171/jns.1986.64.5.0760

32. Latchaw RE, Yonas H, Darby JM, Gur D, Pentheny SL. Xenon/CT cerebral blood flow determination following cranial trauma. Acta Radiol Suppl (1986) 369:370-3.

33. Schalen W, Messeter K, Nordstrom CH. Cerebral vasoreactivity and the prediction of outcome in severe traumatic brain lesions. Acta Anaesthesiol Scand (1991) 35:113-22. doi:10.1111/j.1399-6576.1991.tb03258.x

34. Stringer WA, Hasso AN, Thompson JR, Hinshaw DB, Jordan KG. Hyperventilation-induced cerebral ischemia in patients with acute brain lesions: demonstration by xenon-enhanced CT. AJNR Am J Neuroradiol (1993) 14:475-84.

35. Bouma GJ, Muizelaar JP. Evaluation of regional cerebral blood flow in acute head injury by stable xenon-enhanced computerized tomography. Acta Neurochir Suppl (Wien) (1993) 59:34-40.

36. McLaughlin MR, Marion DW. Cerebral blood flow and vasoresponsivity within and around cerebral contusions. J Neurosurg (1996) 85:871-6. doi:10.3171/jns. 1996.85.5.0871

37. Kelly DF, Martin NA, Kordestani R, Counelis G, Hovda DA, Bergsneider M, et al. Cerebral blood flow as a predictor of outcome following traumatic brain injury. J Neurosurg (1997) 86:633-41. doi:10.3171/jns.1997.86.4.0633

38. Schroder ML, Muizelaar JP, Fatouros P, Kuta AJ, Choi SC. Early cerebral blood volume after severe traumatic brain injury in patients with early cerebral ischemia. Acta Neurochir Suppl (1998) 71:127-30.

39. Bouma GJ, Muizelaar JP, Fatouros P. Pathogenesis of traumatic brain swelling: role of cerebral blood volume. Acta Neurochir Suppl (1998) 71:272-5.

40. Doppenberg EM, Reinert M, Zauner A, Massie TS, Bullock R. Determinants of cerebral extracellular potassium after severe human head injury. Acta Neurochir Suppl (1999) 75:31-4.

41. Kushi H, Moriya T, Saito T, Kinoshita K, Shibuya T, Hayashi N. Importance of metabolic monitoring systems as an early prognostic indicator in severe head injured patients. Acta Neurochir Suppl (1999) 75:67-8. 
42. Hoelper BM, Reinert MM, Zauner A, Doppenberg E, Bullock R. rCBF in hemorrhagic, non-hemorrhagic and mixed contusions after severe head injury and its effect on perilesional cerebral blood flow. Acta Neurochir Suppl (2000) 76: 21-5.

43. von Oettingen G, Bergholt B, Ostergaard L, Jensen LC, Gyldensted C, Astrup J. Xenon CT cerebral blood flow in patients with head injury: influence of pulmonary trauma on the input function. Neuroradiology (2000) 42:168-73. doi:10.1007/s002340050039

44. Schutt S, Horn P, Roth H, Quintel M, Schilling L, Schmiedek P, et al. Bedside monitoring of cerebral blood flow by transcranial thermo-dyedilution technique in patients suffering from severe traumatic brain injury or subarachnoid hemorrhage. J Neurotrauma (2001) 18:595-605. doi:10.1089/ 089771501750291837

45. Valadka AB, Hlatky R, Furuya Y, Robertson CS. Brain tissue PO2: correlation with cerebral blood flow. Acta Neurochir Suppl (2002) 81:299-301.

46. Furuya Y, Hlatky R, Valadka AB, Diaz P, Robertson CS. Comparison of cerebral blood flow in computed tomographic hypodense areas of the brain in head-injured patients. Neurosurgery (2003) 52:340-5; discussion 345-6. doi:10.1227/01.NEU.0000043931.83041.AA

47. Chieregato A, Fainardi E, Tanfani A, Martino C, Pransani V, Cocciolo F, et al. Mixed dishomogeneous hemorrhagic brain contusions. Mapping of cerebral blood flow. Acta Neurochir Suppl (2003) 86:333-7.

48. Chieregato A, Fainardi E, Tanfani A, Sabia G, Martino C, Pascarella R, et al. Induced acute arterial hypertension and regional cerebral flow in intracontusional low density area. Acta Neurochir Suppl (2003) 86:361-5.

49. Chieregato A, Fainardi E, Servadei F, Tanfani A, Pugliese G, Pascarella R, et al. Centrifugal distribution of regional cerebral blood flow and its time course in traumatic intracerebral hematomas. J Neurotrauma (2004) 21:655-66. doi:10.1089/0897715041269669

50. Inoue Y, Shiozaki T, Tasaki O, Hayakata T, Ikegawa H, Yoshiya K, et al. Changes in cerebral blood flow from the acute to the chronic phase of severe head injury. J Neurotrauma (2005) 22:1411-8. doi:10.1089/neu.2005.22.1411

51. Chieregato A, Compagnone C, Tanfani A, Ravaldini M, Tagliaferri F, Pascarella R, et al. Cerebral blood flow mapping in two different subtypes of intraparenchymal hemorrhagic traumatic lesions. Acta Neurochir Suppl (2005) 95:159-64.

52. Poon WS, Ng SC, Chan MT, Lam JM, Lam WW. Cerebral blood flow (CBF)directed management of ventilated head-injured patients. Acta Neurochir Suppl (2005) 95:9-11. doi:10.1007/3-211-32318-X_2

53. Marmarou A, Signoretti S, Aygok G, Fatouros P, Portella G. Traumatic brain edema in diffuse and focal injury: cellular or vasogenic? Acta Neurochir Suppl (2006) 96:24-9. doi:10.1007/3-211-30714-1_6

54. Chieregato A, Tanfani A, Compagnone C, Turrini C, Sarpieri F, Ravaldini M, et al. Global cerebral blood flow and CPP after severe head injury: a xenon-CT study. Intensive Care Med (2007) 33:856-62. doi:10.1007/s00134-007-0604-4

55. Masaoka H. Cerebral blood flow and metabolism during mild hypothermia in patients with severe traumatic brain injury. J Med Dent Sci (2010) 57:133-8.

56. Robertson CS, Gopinath SP, Valadka AB, Van M, Swank PR, Goodman JC. Variants of the endothelial nitric oxide gene and cerebral blood flow after severe traumatic brain injury. J Neurotrauma (2011) 28:727-37. doi:10.1089/ neu.2010.1476

57. Kaloostian P, Robertson C, Gopinath SP, Stippler M, King CC, Qualls C, et al. Outcome prediction within twelve hours after severe traumatic brain injury by quantitative cerebral blood flow. J Neurotrauma (2012) 29:727-34. doi:10.1089/neu.2011.2147

58. Shafer R, Brown A, Taylor C. Correlation between cerebral blood flow and oxygen saturation in patients with subarachnoid hemorrhage and traumatic brain injury. J Neurointerv Surg (2011) 3:395-8. doi:10.1136/jnis.2010.004184

59. Hattori N, Huang SC, Wu HM, Yeh E, Glenn TC, Vespa PM, et al. Correlation of regional metabolic rates of glucose with glasgow coma scale after traumatic brain injury. J Nucl Med (2003) 44:1709-16.

60. Coles JP, Fryer TD, Smielewski P, Rice K, Clark JC, Pickard JD, et al. Defining ischemic burden after traumatic brain injury using 15O PET imaging of cerebral physiology. J Cereb Blood Flow Metab (2004) 24:191-201. doi:10.1097/01.WCB.0000100045.07481.DE

61. Coles JP, Fryer TD, Smielewski P, Chatfield DA, Steiner LA, Johnston AJ, et al. Incidence and mechanisms of cerebral ischemia in early clinical head injury. $J$ Cereb Blood Flow Metab (2004) 24:202-11. doi:10.1097/01.WCB.0000103022. 98348.24
62. Hattori N, Huang SC, Wu HM, Liao W, Glenn TC, Vespa PM, et al. Acute changes in regional cerebral (18)F-FDG kinetics in patients with traumatic brain injury. J Nucl Med (2004) 45:775-83.

63. Wu HM, Huang SC, Hattori N, Glenn TC, Vespa PM, Yu CL, et al. Selective metabolic reduction in gray matter acutely following human traumatic brain injury. J Neurotrauma (2004) 21:149-61. doi:10.1089/089771504322778613

64. Cunningham AS, Salvador R, Coles JP, Chatfield DA, Bradley PG, Johnston AJ, et al. Physiological thresholds for irreversible tissue damage in contusional regions following traumatic brain injury. Brain (2005) 128:1931-42. doi:10.1093/brain/awh536

65. Abdel-Dayem HM, Sadek SA, Kouris K, Bahar RH, Higazi I, Eriksson S, et al. Changes in cerebral perfusion after acute head injury: comparison of CT with Tc-99m HM-PAO SPECT. Radiology (1987) 165:221-6.

66. Roper SN, Mena I, King WA, Schweitzer J, Garrett K, Mehringer CM, et al. An analysis of cerebral blood flow in acute closed-head injury using technetium-99m-HMPAO SPECT and computed tomography. J Nucl Med (1991) 32:1684-7.

67. Ito H, Ishii K, Onuma T, Kawashima R, Fukuda H. Cerebral perfusion changes in traumatic diffuse brain injury; IMP SPECT studies. Ann Nucl Med (1997) 11:167-72. doi:10.1007/BF03164829

68. Wintermark M, Chiolero R, Van Melle G, Revelly JP, Porchet F, Regli L, et al. Relationship between brain perfusion computed tomography variables and cerebral perfusion pressure in severe head trauma patients. Crit Care Med (2004) 32:1579-87. doi:10.1097/01.CCM.0000130171.08842.72

69. Wintermark M, Van Melle G, Schnyder P, Revelly JP, Porchet F, Regli L, et al. Admission perfusion CT: prognostic value in patients with severe head trauma. Radiology (2004) 232:211-20. doi:10.1148/radiol.2321030824

70. Soustiel JF, Mahamid E, Goldsher D, Zaaroor M. Perfusion-CT for early assessment of traumatic cerebral contusions. Neuroradiology (2008) 50:189-96. doi:10.1007/s00234-007-0337-7

71. Huang AP, Lee CW, Hsieh HJ, Yang CC, Tsai YH, Tsuang FY, et al. Early parenchymal contrast extravasation predicts subsequent hemorrhage progression, clinical deterioration, and need for surgery in patients with traumatic cerebral contusion. J Trauma (2011) 71:1593-9. doi:10.1097/TA. 0b013e31822c8865

72. Bendinelli C, Bivard A, Nebauer S, Parsons MW, Balogh ZJ. Brain CT perfusion provides additional useful information in severe traumatic brain injury. Injury (2013) 44:1208-12. doi:10.1016/j.injury.2013.03.039

73. Garnett MR, Blamire AM, Corkill RG, Rajagopalan B, Young JD, CadouxHudson TA, et al. Abnormal cerebral blood volume in regions of contused and normal appearing brain following traumatic brain injury using perfusion magnetic resonance imaging. J Neurotrauma (2001) 18:585-93. doi:10.1089/089771501750291828

74. Hagen T, Bartylla K, Piepgras U. Correlation of regional cerebral blood flow measured by stable xenon CT and perfusion MRI. J Comput Assist Tomogr (1999) 23:257-64. doi:10.1097/00004728-199903000-00015

75. Rempp KA, Brix G, Wenz F, Becker CR, Guckel F, Lorenz WJ. Quantification of regional cerebral blood flow and volume with dynamic susceptibility contrastenhanced MR imaging. Radiology (1994) 193:637-41.

76. Gillard JH, Minhas PS, Hayball MP, Bearcroft PW, Antoun NM, Freer CE, et al. Assessment of quantitative computed tomographic cerebral perfusion imaging with H2(15)O positron emission tomography. Neurol Res (2000) 22:457-64.

77. Campbell BC, Christensen S, Levi CR, Desmond PM, Donnan GA, Davis SM, et al. Comparison of computed tomography perfusion and magnetic resonance imaging perfusion-diffusion mismatch in ischemic stroke. Stroke (2012) 43:2648-53. doi:10.1161/STROKEAHA.112.660548

78. Sokoloff L, Reivich M, Kennedy C, Des Rosiers MH, Patlak CS, Pettigrew KD, et al. The [14C]deoxyglucose method for the measurement of local cerebral glucose utilization: theory, procedure, and normal values in the conscious and anesthetized albino rat. J Neurochem (1977) 28:897-916. doi:10.1111/j.14714159.1977.tb10649.x

79. Reivich M, Kuhl D, Wolf A, Greenberg J, Phelps M, Ido T, et al. The [18F]fluorodeoxyglucose method for the measurement of local cerebral glucose utilization in man. Circ Res (1979) 44:127-37. doi:10.1161/01.RES.44.1.127

80. Ter-Pogossian MM, Eichling JO, Davis DO, Welch MJ. The measure in vivo of regional cerebral oxygen utilization by means of oxyhemoglobin labeled with radioactive oxygen-15. J Clin Invest (1970) 49:381-91. doi:10.1172/JCI106247

81. Frackowiak RS, Lenzi GL, Jones T, Heather JD. Quantitative measurement of regional cerebral blood flow and oxygen metabolism in man using $15 \mathrm{O}$ 
and positron emission tomography: theory, procedure, and normal values. J Comput Assist Tomogr (1980) 4:727-36. doi:10.1097/00004728-19801200000001

82. Herscovitch P, Markham J, Raichle ME. Brain blood flow measured with intravenous H2(15)O. I. Theory and error analysis. J Nucl Med (1983) 24: 782-9.

83. Reivich M, Kuhl D, Wolf A, Greenberg J, Phelps M, Ido T, et al. Measurement of local cerebral glucose metabolism in man with 18F-2-fluoro-2-deoxy-dglucose. Acta Neurol Scand Suppl (1977) 64:190-1.

84. Pickard JD, Hutchinson PJ, Coles JP, Steiner LA, Johnston AJ, Fryer TD, et al. Imaging of cerebral blood flow and metabolism in brain injury in the ICU. Acta Neurochir Suppl (2005) 95:459-64. doi:10.1007/3-211-32318-X_94

85. Menon DK. Brain ischaemia after traumatic brain injury: lessons from $15 \mathrm{O} 2$ positron emission tomography. Curr Opin Crit Care (2006) 12:85-9. doi:10.1097/01.ccx.0000216572.19062.8f

86. Kato T, Nakayama N, Yasokawa Y, Okumura A, Shinoda J, Iwama T. Statistical image analysis of cerebral glucose metabolism in patients with cognitive impairment following diffuse traumatic brain injury. J Neurotrauma (2007) 24:919-26. doi:10.1089/neu.2006.0203

87. Clausen T, Zauner A, Levasseur JE, Rice AC, Bullock R. Induced mitochondrial failure in the feline brain: implications for understanding acute post-traumatic metabolic events. Brain Res (2001) 908:35-48. doi:10.1016/S0006-8993(01) 02566-5

88. Nielsen TH, Bindslev TT, Pedersen SM, Toft P, Olsen NV, Nordstrom CH. Cerebral energy metabolism during induced mitochondrial dysfunction. Acta Anaesthesiol Scand (2013) 57:229-35. doi:10.1111/j.1399-6576.2012.02783.x

89. Nortje J, Gupta AK. The role of tissue oxygen monitoring in patients with acute brain injury. Br J Anaesth (2006) 97:95-106. doi:10.1093/bja/ael137

90. Levin CS. Primer on molecular imaging technology. Eur J Nucl Med Mol Imaging (2005) 32:S325-45. doi:10.1007/s00259-005-1973-y

91. Devous MD Sr. Single-photon emission computed tomography in neurotherapeutics. NeuroRx (2005) 2:237-49. doi:10.1602/neurorx.2.2.237

92. Raji CA, Tarzwell R, Pavel D, Schneider H, Uszler M, Thornton J, et al. Clinical utility of SPECT neuroimaging in the diagnosis and treatment of traumatic brain injury: a systematic review. PLoS One (2014) 9:e91088. doi:10.1371/journal.pone.0091088

93. Hillman J, Sturnegk P, Yonas H, Heron J, Sandborg M, Gunnarsson T, et al. Bedside monitoring of CBF with xenon-CT and a mobile scanner: a novel method in neurointensive care. Br J Neurosurg (2005) 19:395-401. doi:10.1080/02688690500389898

94. Sturnegk P, Mellergard P, Yonas H, Theodorsson A, Hillman J. Potential use of quantitative bedside CBF monitoring (Xe-CT) for decision making in neurosurgical intensive care. Br J Neurosurg (2007) 21:332-9. doi:10.1080/ 02688690701411574

95. Carlson AP, Brown AM, Zager E, Uchino K, Marks MP, Robertson C, et al. Xenon-enhanced cerebral blood flow at $28 \%$ xenon provides uniquely safe access to quantitative, clinically useful cerebral blood flow information: a multicenter study. AJNR Am J Neuroradiol (2011) 32:1315-20. doi:10.3174/ ajnr.A2522

96. Wintermark M, Sesay M, Barbier E, Borbely K, Dillon WP, Eastwood JD, et al. Comparative overview of brain perfusion imaging techniques. Stroke (2005) 36:e83-99. doi:10.1161/01.STR.0000177884.72657.8b

97. Seifert H, Blass G, Leetz HK, Voges M. The radiation exposure of the patient from stable-xenon computed tomography. Br J Radiol (1995) 68:301-5. doi:10.1259/0007-1285-68-807-301

98. Barbier EL, Lamalle L, Decorps M. Methodology of brain perfusion imaging. J Magn Reson Imaging (2001) 13:496-520. doi:10.1002/jmri.1073

99. Grandin CB. Assessment of brain perfusion with MRI: methodology and application to acute stroke. Neuroradiology (2003) 45:755-66. doi:10.1007/s00234003-1024-y

100. Rosen BR, Belliveau JW, Vevea JM, Brady TJ. Perfusion imaging with NMR contrast agents. Magn Reson Med (1990) 14:249-65. doi:10.1002/mrm.1910140211

101. Lia TQ, Guang Chen Z, Ostergaard L, Hindmarsh T, Moseley ME. Quantification of cerebral blood flow by bolus tracking and artery spin tagging methods. Magn Reson Imaging (2000) 18:503-12. doi:10.1016/S0730-725X(00)00137-5

102. Sorensen AG, Buonanno FS, Gonzalez RG, Schwamm LH, Lev MH, HuangHellinger FR, et al. Hyperacute stroke: evaluation with combined multisection diffusion-weighted and hemodynamically weighted echo-planar MR imaging. Radiology (1996) 199:391-401.

103. Baird AE, Benfield A, Schlaug G, Siewert B, Lovblad KO, Edelman RR, et al. Enlargement of human cerebral ischemic lesion volumes measured by diffusion-weighted magnetic resonance imaging. Ann Neurol (1997) 41:581-9. doi:10.1002/ana.410410506

104. Staroselskaya IA, Chaves C, Silver B, Linfante I, Edelman RR, Caplan L, et al. Relationship between magnetic resonance arterial patency and perfusiondiffusion mismatch in acute ischemic stroke and its potential clinical use. Arch Neurol (2001) 58:1069-74. doi:10.1001/archneur.58.7.1069

Conflict of Interest Statement: The authors declare that the research was conducted in the absence of any commercial or financial relationships that could be construed as a potential conflict of interest.

Received: 07 April 2014; accepted: 16 June 2014; published online: 07 July 2014.

Citation: Rostami E, Engquist H and Enblad P (2014) Imaging of cerebral blood flow in patients with severe traumatic brain injury in the neurointensive care. Front. Neurol. 5:114. doi: 10.3389/fneur.2014.00114

This article was submitted to Neurotrauma, a section of the journal Frontiers in Neurology.

Copyright (c) 2014 Rostami, Engquist and Enblad. This is an open-access article distributed under the terms of the Creative Commons Attribution License (CC BY). The use, distribution or reproduction in other forums is permitted, provided the original author(s) or licensor are credited and that the original publication in this journal is cited, in accordance with accepted academic practice. No use, distribution or reproduction is permitted which does not comply with these terms. 